\title{
Effect of estradiol, vitamin A, E and selenium treatment with varying sexual rest period on recovery rate in cross-bred cows with chronic endometritis
}

\author{
Dipyaman Sengupta ${ }^{1}$, Pramod R. Nandi ${ }^{2}$
}

1. All Indian Coordinated Research Project on Integrated Farming System, Bidhan Chandra Krishi Viswavidyalaya, Kalyani-741252, West Bengal, India, 2. Department of Veterinary Gynaecology, West Bengal University of Animal \& Fishery Sciences, Belgachia, Kolkata-37, West Bengal, India

Corresponding author: Dipyaman Sengupta, email: dipyamansengupta1@gmail.com Received: 22-05-2012, Accepted: 05-07-2012, Published online: 17-12-2012

How to cite this article: Sengupta D and Nandi PR (2013) Effect of estradiol, vitamin A, E and selenium treatment with varying sexual rest period on recovery rate in cross-bred cows with chronic endometritis, Vet World 6(2): 106-108. doi: 10.5455/vetworld.2013.106-108

\begin{abstract}
Aim:This work was done to study the effect of vitamin A, E and Se with varying sexual rest period in cross-bred cows with chronic endometritis.

Materials and Methods: Cross-bred cows ( $\mathrm{n}=396)$ from different villages of West Bengal with purulent or muco-purulent discharge with a history of infertility and repeat breeding for 3 to 6 months were chosen for the present study. These cows received uterine wash with lugol's iodine, intra-uterine and parenteral antibiotics and de-worming as general treatment. They were then divided into six groups viz. SR12 $\times \operatorname{EV}(n=59), S R 12 \times \operatorname{Control}(n=67), S R 21 \times E V(n=65), S R 21 \times \operatorname{Control}(n=70)$, SR24 $\times$ EV (n=66), SR24 $\times$ Control (n=69) receiving sexual rest of 12 (SR12), 21 (SR21) and 24 (SR24) days with (EV group) or without (control) estradiol + vitamin A, E and Se.

Results: The results indicate that the recovery rate of $\mathrm{EV}$ and control group was $76.27 \%$ and $37.31 \%$ respectively $(\mathrm{P}<0.01)$ in SR $12,72.31 \%$ and $47.14 \%$ respectively $(\mathrm{P}<0.01)$ in SR 21 and $92.41 \%$ and $63.77 \%$ respectively $(\mathrm{P}<0.01)$ in SR 24 . SR 24 showed significantly better $(\mathrm{P}<0.01)$ recovery rate compared to SR 12 and SR 21 . Lowest recovery and conception rate of EV and control group in SR 12 might be due to insufficient time for the recovery of endometrium.

Conclusion: The results indicate that parenteral and intra-uterine antibiotics had synergistic effect with estradiol, vitamin A, E and Se treatment in recovery from endometritis, though a minimum time interval is required for complete recovery of the endometrium for best conception rate.
\end{abstract}

Key words: endometritis, estradiol, progesterone, selenium, sexual rest, vitamin A, vitamin E

\section{I ntroduction}

Chronic endometritis of cross bred cattle is a wide spread problem in different districts of West Bengal. These repeat breeders are often presented during estrous for insemination with purulent or mucopurulent uterine discharges. As estradiol increases the endometrial blood supply, stimulates uterine defense mechanism [1] and vitamin A, E and Se are important antioxidants and their deficiency have been proved to predispose the endometrium to further infection and delaying recovery [2].

This work was done to study the effect of vitamin $\mathrm{A}, \mathrm{E}$ and Se with varying sexual rest period in crossbred cows with chronic endometritis.

\section{Materials and Methods}

396 cross bred cows from different villages of Gaighata Gram Panchayat, Dist. 24 Parganas (North), West Bengal were selected for conducting the present work. These cows were presented for artificial insemination with purulent or muco-purulent vaginal discharge and history of repeat breeding and infertility for 3 to 6 months.

These experiments were conducted in accordance with the guidelines laid down by EU directive 2010/
63/EU for animal experiments.

General treatment was given for repeat breeders

1. Uterus was washed with Lugol's iodine on the day of heat and 2 bolii of $200 \mathrm{mg}$ furazolidone and $1 \mathrm{~g}$ metronidazole (Fazole, Unichem Laboratories Ltd.) was infused in each uterine horn.

2. Cows were treated with oxytetracyclin $(7 \mathrm{mg} / \mathrm{kg}$ body wt.) intramuscularly for 3 consecutive days starting from the day of heat (day 0 ).

3. Deworming of all animals by albendazole.

The cows were divided into three groups having sexual rest periods of 12 days (SR 12), 21 days (SR 21) and 24 days (SR 24). The group having 24 days sexual rest had an intermittent estrous on day 12 when the cows were not bred. These cows were brought to heat on day 12 either by intra-muscular injection of $10 \mathrm{mg}$ estradiol (Progynon Depot, United Pharmacies) on days $9 \& 10$ of estrous cycle plus injection of $30 \mathrm{IU}$ oxytocin (Syntocinon, Novartis Pharma Ltd.) on day

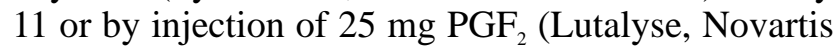
India Ltd.) on day 10. Each sexual rest group was further divided into two groups that received the following treatment:

1. Control (C): This group received general treatment only. The control group of SR 12 and SR 24 
was brought to heat on day 12 by injection of $25 \mathrm{mg}$ $\mathrm{PGF}_{2}$ on day 10 as stated earlier.

2. Estradiol + Vitamin treated $(\mathrm{EV})$ : This group received general treatment + intramuscular injection of $10 \mathrm{mg}$ estradiol valerate on days 2 to 4 of estrous cycle and twice weekly injection of vitamin E, Se $(10 \mathrm{ml} \mathrm{E}$ care SE, Vetcare) and weekly injection of 18,00,000 IU vitamin A (Glaxo Smith Kline Pharmaceuticals Ltd.) starting from the day of heat till next heat or insemination. The cows of SR 12 and SR 24 group were brought to heat on day 12 by injection of estradiol + oxytocin as stated earlier.

The experimental design and distribution of animals in each group is presented as follows:

$\begin{array}{lccc}\text { Sexual Rest(SR) } & \text { Control (c) } & \begin{array}{c}\text { Estradiol +Vitamin } \\ \text { (EV) treated }\end{array} & \text { Tota } \\ \text { SR (12) } & 67 & 59 & 126 \\ \text { SR(21) } & 70 & 65 & 135 \\ \text { SR(24) } & 69 & 66 & 135 \\ \text { Total } & 206 & 190 & 396\end{array}$

Observations: The treated cows were observed on their subsequent estrous for endometritis and were inseminated if found negative. All inseminated cows of EV group were injected (deep i.m.) with 500 mg Hydroxyprogesterone Caproate (Duraprogen, Unichem Laboratories Ltd.) on days 1, 3 and 5 of estrous. The cows were considered to have recovered from endometritis if the vaginal discharge was clear, watery, and transparent free from whitish or yellowish flakes or pus. All inseminated cows were diagnosed for pregnancy on day 60 if they did not return to heat on day 21 .

The number of cows recovered from endometritis and inseminated along with their conception rate was compared among various treatment groups by chisquare test.

\section{Results}

The control and EV group in SR 12 did not differ $(P>0.05)$ in their conception rate (Table-1) unlike in SR 21 and SR 24 where the difference was highly significant $(P<0.01)$. The conception rate of control group in SR 12 and SR 21 did not differ significantly $(P>0.05)$, but the difference was significant $(P<0.05)$ compared to SR 24. Significant difference in conception rate of EV group was observed among SR $12(26.67 \%)$ vs SR $21(53.19 \%)$ and SR $21(53.19 \%)$ vs SR $24(75.41 \%)$.
Among control groups the best conception rate (CR) was observed in SR 24 (Table-1), the difference in CR being non-significant $(P>0.01)$ between SR 12 \& SR 21 groups. Among EV groups also, the best CR was found in SR 24 but the CR of SR 21 was significantly $(P<0.01)$ better than SR 12. EV X SR 12 group also exhibited maximum number of embryonic deaths indicated by non-return to heat by day 21 and nonpregnant by day 60 .The conception rate of 60 normal inseminations was comparable with SR 21 and control of SR 24, but differed significantly from EV treated group of SR 24.

\section{Discussion}

The EV treated cows of SR 12 and SR 24 were brought to heat on day 12 by intramuscular injection of estradiol and oxytocin. Estradiol and oxytocin induces the release of $\mathrm{PGF}_{2 \alpha}$ from the endometrium $[3,4]$ thus resulting in early luteolysis and estrus. This treatment proved to be much cheaper than use of $\mathrm{PGF}_{2 \alpha}$ analogues.

The results indicate that estradiol and vitamin A, $\mathrm{E}$ and Se treatment increased the rate of recovery in cows with endometritis. It has been found that intrauterine infusion of estradiol, oxytetracyclin and cloprostenol individually to cows with endometritis did not result in any significant difference in recovery rate [5] but the treatment to conception interval for all successful treatments of endometritis by cloprostenol was shorter than for estradiol (68.3 v 86.4 days, $\mathrm{P}<$ 0.02 ), and the interval for oxytetracycline was shorter than for oestradiol $(70.2 \vee 86.4$ days, $\mathrm{P}<0.05)$. No reduction in the incidence of postpartum metritis in cows treated with estradiol compared to control has been found by some workers [6,7]. Our findings differed from these authors probably due to the synergistic effect of parenteral and intra-uterine antibiotics with estradiol by stimulation of endometrial blood flow and increasing uterine leukocytic response [8] as well as antioxidant and tissue regenerative properties of vitamin A, E and Se [2,9]. More recently Selenium has also been found to stimulate uterine defence mechanism [10] besides its protective action as an anti-oxidant.

Lowest recovery and conception rate of EV and control group in SR 12 might be due to insufficient time for the recovery of endometrium. This is further

Table-1. Recovery and conception rate of cross bred cows with chronic endometritis receiving general treatment along with estradiol + vitamin A, E and Se with varying period of sexual rest.

\begin{tabular}{|c|c|c|c|c|c|c|}
\hline \multirow[t]{2}{*}{ Items } & \multicolumn{2}{|c|}{ Sexual Rest 12} & \multicolumn{2}{|c|}{ Sexual Rest 21} & \multicolumn{2}{|c|}{ Sexual Rest 24} \\
\hline & Control & EV treated & Control & EV treated & Control & EV treated \\
\hline Total number of cows & 67.00 & 59.00 & 70.00 & 65.00 & 69.00 & 66.00 \\
\hline No. of cows recovered and inseminated & 25.00 & 45.00 & 33.00 & 47.00 & 44.00 & 61.00 \\
\hline Percent recovered & 37.31 & 76.27 & 47.14 & 72.31 & 63.77 & 92.42 \\
\hline No. of unrecovered cows & 40.00 & 14.00 & 37.00 & 18.00 & 25.00 & 5.00 \\
\hline No. of inseminated cows conceived & 5.00 & 12.00 & 10.00 & 25.00 & 24.00 & 46.00 \\
\hline Conception rate (\%) & 20.00 & 26.67 & 30.30 & 53.19 & 54.55 & 75.41 \\
\hline Not conceived & 20.00 & 33.00 & 23.00 & 22.00 & 20.00 & 15.00 \\
\hline Non-return to heat on day 21 , but not pregnant & 10.00 & 17.00 & 5.00 & 2.00 & - & - \\
\hline \multicolumn{2}{|l|}{$\begin{array}{l}\text { Number conceived out of } 60 \text { normal inseminations } \\
\text { CR }(\%) \text { of } 60 \text { normal inseminations }\end{array}$} & 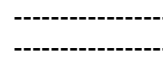 & ----- 32 & - & & \\
\hline
\end{tabular}


emphasized by the fact that seventeen and ten recovered and inseminated cows of EV and control group respectively did not return to heat on day 21 but were found non-pregnant on day 60 . These cows had embryonic deaths and were anestrous with persistent corpus luteum. The endometrium of these cows did not regenerate completely for successful conception and/or had latent infection (sub-clinical endometritis).

The EV group of SR 24 exhibited best recovery and conception rates indicating that a break in the exposure of endometrium to progesterone in SR 24 is much more effective than continued progesterone exposure in SR21. This is due to the fact that continued progesterone exposure favours uterine infection due to immunosuppression [11,12]. Moreover, endometrial $\mathrm{PGF}_{2 \alpha}$ release midway (around day 12) in SR 24 by estradiol + oxytocin might have resulted in better recovery in SR 24 due to neutrophil chemotaxis and bacterial ingestion caused by $\mathrm{PGF}_{2 \alpha}[13,14]$. Better CR observed in EV groups (barring SR 12) is not only due to greater recovery of the endometrium but also due to early progesterone treatment that has been found to hasten conceptus growth with greater conceptus survivality [14,15]. Another possible reason for improved CR in EV group is due to anti-oxidant effect of Selenium as it has been found that oxidative stress influences the oocyte and embryo quality and thus the fertilization rates [16].

\section{Conclusion}

Thus from this study it can be concluded that treatment of bovine endometritis with minimum investment of time and money ensuring best recovery and good conception rate can be had if the cows are given a sexual rest for two estrous periods, the period of estrus being reduced to 12 days. Moreover the cows can be brought to heat by injection of estradiol and oxytocin in place of $\mathrm{PGF}_{2 \alpha}$ and this is much cheaper and more effective as has been found in this study. Treatment of recovered and inseminated cows with progesterone early in the estrous cycle results in better conception rate.

\section{Author's Contribution}

DS was involved in planning and execution of the treatment protocols, obtaining results and data analysis PRN contributed with his valuable and critical suggestions as well as drafted and revised the manuscript. Both authors read and approved the final manuscript.

\section{Acknowledgements}

Authors acknowledge AICRPon Integrated Farming System, Bidhan Chandra Krishi Viswavidyalaya, Kalyani, PIN- 741252 for their kind and liberal help in conducting the following survey work in different villages of Gaighata Block, West Bengal. The present work has been done in our own interest.

\section{Competing interests}

Authors declare that they have no competing interest.

\section{References}

1. Roberts, S. J. (1982). Veterinary Obstetrics and Genital Diseases, $2^{\text {nd }}$ (Indian) Edn., CBS Publishers \& Distributors.

2. Spears, J. W. and Weiss, W. P. (2008). Role of antioxidants and trace elements in health and immunity of transition dairy cows. Vet. J. 176(1): 70-76.

3. Kotwica, G., Oponowicz, A., Kurowicka, B., Franczak, A. and Bogacka, I. (2010). The effect of progesterone on oxytocin stimulated intracellular $\mathrm{Ca}^{2+}$ metabolism and prostaglandin secretion in porcine endometrium. Pol. J. Vet. Sci. 13(4): 815-822.

4. Araujo, R. R., Ginther, O. J., Ferreira, J. C., Palhao, M. M., Beq, M. A., Wiltbank, M. C. (2009). Role of follicular estradiol-17beta in timing of luteolysis in heifers. Biol. of Reprod. 81(2): 426-37.

5. Sheldon, I. M. and Noakes, D. E. (1998). Comparison of three treatments for bovine endometritis. Vet. Rec. 142: 575579.

6. Overton, M. W., Sischo, W. M. and Reynolds, J. P. (2003). Evaluation of effect of estradiol cypionate administered prophylactically to postparturient dairy cows at high risk for metritis. JAm Vet MedAssoc 223(6): 846-851.

7. Sheldon, I. M., Noakes, D. E., Rycroft, A. N. and Dobson, H. (2004). Effect of intrauterine administration of estradiol on postpartum uterine infection in cattle. Anim. Reprod.Sci. 81(1-2): 13-23.

8. Dhaliwal, G. S., Murray, R. D. and Woldehiwet, Z. (2001). Some aspects of immunology of the bovine uterus related to treatments for bovine endometritis. Animal Reproduction Science. 67: 135-152.

9. Kaewtamun, W., Okouyi, M., Humblot, P., Techakumphu, A. A., Ponter, A. A. 2011. Does supplementing dairy cows with $\beta$-carotene during the dry period affect postpartum ovarian activity, progesterone, and cervical and uterine involution? Theriogenology. 75(8): 1029-1038.

10. Thatcher, W., Santos, J. E. P. and Staples, C. R. (2011). Dietary manipulation to improve embryonic survival in cattle. Theriogenology. 78(9): 1619-1631.

11. Hansen, P. J. (2007). Regulation of immune cells in the uterus during pregnancy in ruminants. J. Anim. Sci. 85(13): E30-E31.

12. Sheldon, I. M., Cronin, J., Goetze, L., Donofrio, G., Schuberth, H. J. (2009). Defining postpartum uterine defence and the mechanism of infection and immunity in the female reproductive tract in cattle. Biology of Reprod. 81(6): 1025-1032.

13. Lewis, S. (2003). Steroidal regulation of uterine resistance to bacterial infection in livestock. Reproductive Biology and Endocrinology 1: 117.

14. Weens, C. W., Weens, Y. S. and Rander, R. D. (2006). Prostaglandin and reproduction in female farm animals. The Veterinary Journal. 171: 206-228.

15. Bazer, F. W., Song, G. and Thatcher, W. W. (2012). Role of conceptus secretary proteins in establishment and maintenance of pregnancy in ruminants. Asian-Aust. $J$. Anim. Sci. 25(1): 1-16.

16. Diskin, M. G., Stronge, A. J. H., Morris, D. G., Kenny, D. A., and Sreenan, J. M. (2004). The association between early luteal phase concentrations of progesterone and embryo survival in heifers and dairy cows. J. Anim. Sci. 82: 101-103. 